\title{
Synergistic Antioxidant Activity of Clove Oleoresin with Capsicum Oleoresin and Kalonji Seeds Extract in Sunflower Oil
}

\author{
D Mitic Culafic* \\ Faculty of Biology, University of Belgrade, Serbia \\ Received: February 02, 2018; Published: April 10, 2018 \\ *Corresponding author: D Mitic Culafic, Faculty of Biology, University of Belgrade, Studentski trg 16, Belgrade, 11000, Serbia, \\ Email: mdragana@bio.bg.ac.rs
}

\begin{abstract}
The essential fatty acids are one of the vital nutrients to be included in the diet. However, they are susceptible to autoxidation and maintaining their stability during storage is a foremost problem. Synthetic antioxidants used at present are reported to be toxic in nature. Hence, there is a demand from consumers for foods containing natural antioxidants. Various natural products like clove oleoresin, capsicum oleoresin and kalonji seeds are known to show substantial antioxidant activity. Their activity can be improved by studying structural aspects and evaluating their synergism. The current investigation aims to fractionate clove oleoresin by means of column chromatography isolating the eugenol rich fraction. Though clove oleoresin showed pro-oxidant effect, its eugenol rich fraction showed marginal antioxidant activity in sunflower oil. The clove oleoresin and capsicum oleoresin, both showed good antioxidant activity in synergism with kalonji seeds extract. The study indicated the synergistic potential of natural antioxidants to be used as a substitute for synthetic antioxidants.
\end{abstract}

Keywords: Sunflower Oil; Natural Antioxidants; Clove; Synergistic Activity; Kalonji; Capsicum

Abbreviations: TBHQ: Butylhydroquinone; RSFO: Refined Sunflower Oil; BHT: Butylhydroxyltoluene; BHA: Butylhydroxylanisole; KEE: Kalonji Seeds Ethanol Extract

\section{Introduction}

Vegetable oils such as flaxseed, soybean, safflower and sunflower are the richest sources of essential fatty acids (EFAs). Owing to the role of these EFAs to perform significant functions in human body [1] and the fact that they cannot be produced in human body, EFAs need to be provided through diet. Concurrently, being unsaturated, they are vulnerable to autoxidation. Ultimately, they have a very short shelf life if they are not stored with an antioxidant. The synthetic antioxidants used for the same purpose are tertiary Butylhydroquinone (TBHQ), Butylhydroxyltoluene (BHT) and Butylhydroxylanisole (BHA). Because of the unsafe nature of these synthetic antioxidnats [2] and the consumers' approach towards the natural ingredients, research is now oriented towards the search for novel natural antioxidants. Several studies have analyzed the antioxidant potential of a wide variety of vegetables and fruits [3]. Extracts from spices, herbs and hulls are examined to have various degrees of antioxidant activity [4,5]. The presence of active components in spices has been demonstrated over the last 30 years [6].

The antioxidant activity of clove, capsicum and kalonji seeds are because of eugenol [7], capsaicinoids [8] and thymol, thymoquinone, carvacrol [9] respectively. Moreover, the activity of the antioxidant in the extract is affected by the presence of other components in the extract [10] and there is a scope to improve the antioxidant activity of the extract using synergistic effect with combination of these extracts. Besides possessing the antioxidant activity, these natural extracts possess medicinal benefits as well. Clove has been reported to possess therapeutic use in dental application [11]. It has antiprotozoal [12], antibacterial [13] and anti-inflammatory activity [14]. It is known to possess immunomodulatory effects [15]. Equally, capsicum has been valued for its various medicinal actions including antilithogenic, anti-inflammatory and analgesic effects. It has cardio protective, thermogenic influence and also beneficial effects on gastrointestinal system. Capsicum has the potential for pain relief, cancer prevention and weight loss [16].

Likewise, the seeds of kalonji have various curative actions. Haseena et al. [17] reviewed the positive effect of kalonji seeds on male reproductive system. Recently, Randhawa and Alenazi [18] have also listed analgesic, antipyretic, anti-parkinsonism, anticonvulsant, antidepressant, antianxiety, neuroprotective effects of kalonji seeds. They have also elaborated the effect of the same on tolerance, learning, memory and encephalitis. Thus, by 
using these natural ingredients as a source of antioxidant, their therapeutic benefits can be accomplished simultaneously. It was suggested previously that better results are often achieved by using a combination of two or more antioxidants [19]. The present work deals to envisage the effect of purification on the antioxidant activity of clove oleoresin. The work is extrapolated to study the synergistic effect of clove oleoresin with kalonji seeds extract and capsicum oleoresin.

\section{Materials and Methods}

\section{Materials}

Refined sunflower oil (RSFO) was received as a gift sample from M/s Cargill India Pvt. Ltd., New Delhi. Capsicum oleoresin and clove oleoresin were obtained from Kancor India Ltd., Angamaly South, India. Kalonji seeds were procured from local vendor. All other chemical reagents and solvents were obtained from s.d. FIfiNECHEM LiIMIiTEDd, Mumbai.

\section{Analysis of Capsicum Oleoresin and Clove Oleoresin}

The presence of capsaicinoids was checked by UV spectrometry (Shimadzu UV-1601) of capsicum oleoresin in isopropanol [20]. The presence of eugenol in clove oleoresin was detected by HPTLC using mobile phase, n-hexane: ethyl acetate (3:1 v/v) [21]. The spots were visualized in UV chamber at $254 \mathrm{~nm}$.

\section{Extraction of Kalonji Seeds}

Kalonji seeds ( $50 \mathrm{~g}$ ) were crushed and extracted using ethanol in Soxhlet extractor ( $400 \mathrm{~mL}$ capacity) for 3 hours. The crude kalonji seeds ethanol extract (KEE) was obtained after removal of solvent using rotary vacuum evaporator.

\section{Fractionation of Clove Oleoresin to Eugenol Rich Frac- tion (ERF)}

Previously dried silica gel (60-120 mesh) weighing $180 \mathrm{~g}$ was slurried in n-hexane and filled in a glass column of $3.3 \mathrm{~cm}$ internal diameter and $35 \mathrm{~cm}$ height. Clove oleoresin weighing $9.0 \mathrm{~g}$ was dissolved in $10 \mathrm{~mL}$ of $\mathrm{n}$-hexane and loaded on the silica gel column. Further the column was continuously eluted with n-hexane: ethyl acetate $(3: 1 \mathrm{v} / \mathrm{v})$ at $1 \mathrm{~mL} / \mathrm{min}$. Each $10 \mathrm{~mL}$ fraction was separately collected and analyzed by HPTLC on silica gel plates (Merck DC Kieselgel 60 F254) using n-hexane: ethyl acetate (3:1 v/v) [21] as mobile phase. The spots were visualized in UV chamber at 254 $\mathrm{nm}$. The fractions rich in eugenol were combined and solvent was removed to get ERF. The concentration of eugenol in ERF was determined by Gas Chromatography at Sophisticated Analytical Instrument Facility (SAIF), IIT-Bombay, Mumbai, India.

\section{Study of Antioxidant Activity}

The various blends of oil containing combinations of capsicum oleoresin $(2.5 \% \mathrm{w} / \mathrm{v})$, clove oleoresin $(0.5 \%, 1.5 \% \mathrm{w} / \mathrm{v})$ and KEE $(2 \% \mathrm{w} / \mathrm{v})$ were prepared. The oxidative stability of oil blends was checked at $60^{\circ} \mathrm{C}$ for 30 days at regular interval of 5 days according to the AOCS Official Methods [22] by peroxide value (in meq/kg) (PV, Method Cd 8-53), p-anisidine value (p-A.V., Method Cd 18-90) and total oxidation (Totox) value (in meq/kg) (Method Cg 3-91). All the experiments were carried out in triplicate and the values were expressed as arithmetic mean of the experiments along with standard deviation. At $60^{\circ} \mathrm{C}$, the rate of oxidation is raised but the mechanism of oxidation remains identical as that of the ambient temperature [23]. The antioxidant activities of natural antioxidants were compared with the control sample and TBHQ (200ppm) under the same conditions. The relative antioxidant activities were compared using Oxidative Factor (OXF) for antioxidants using following formula [24],

$$
\left.\left.O X F=\mathbb{(}\left(P V_{-} \text {final }-P V_{-} \text {initial }\right) \rrbracket_{-} \text {antioxidant }\right) / \mathbb{(}\left(P V_{-} \text {final }-P V_{-} \text {initial }\right) \rrbracket_{-} \text {control }\right)
$$

Where PVs indicate the mean values of all triplicate determinations of the peroxide value.

\section{Results and Discussion}

\section{Analysis of Capsicum Oleoresin and Clove Oleoresin}

The presence of capsaicinoids in capsicum oleoresin was confirmed by the peak at $281 \mathrm{~nm}$ in the UV spectrum given by the solution of capsicum oleoresin in isopropanol [20]. The capsaicinoids content in capsicum oleoresin was found to be $3.14 \%$. Clove oleoresin contains eugenol as an active constituent along with other constituents (Figure 1). The eugenol content in clove oleoresin was detected as $66.7 \%$ by HPTLC. The Rf value of the eugenol was obtained to be 0.89 . The eugenol was purified by column chromatography and analyzed by HPTLC (Figure 2). The purity of ERF was found to be $68 \%$ by Gas Chromatography.

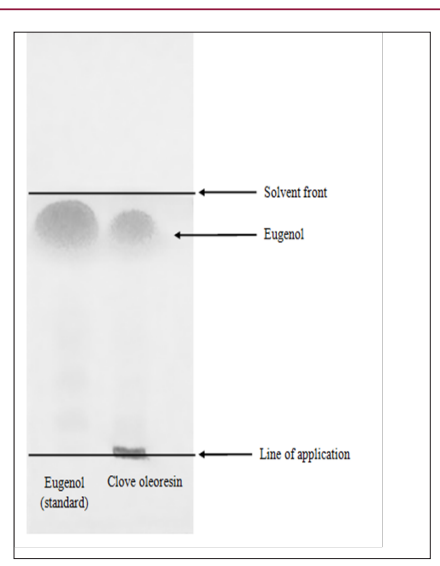

Figure 1: Thin layer chromatography of standard eugenol and clove oleoresin.

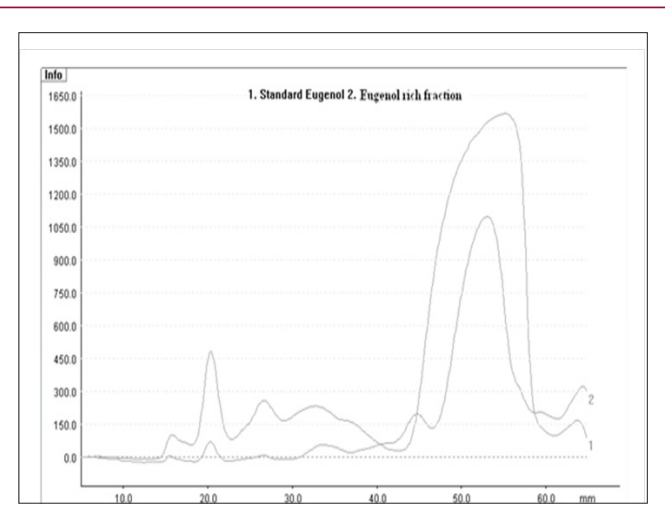

Figure 2: Overlay of HPTLC chromatogram of standard eugenol and eugenol rich fraction. 


\section{Activity of clove oleoresin and ERF in RSFO}

Table 1: Effect of synergism of clove oleoresin with capsicum oleoresin and KEE on oxidative stability (peroxide formation) of refined sunflower oil without antioxidant (RSFO) at $60^{\circ} \mathrm{C}$.

\begin{tabular}{|c|c|c|c|c|c|c|}
\hline \multicolumn{7}{|c|}{ OXF } \\
\hline Sample $\begin{array}{c}\text { Time } \\
\text { (days) }\end{array}$ & $\mathbf{5}$ & $\mathbf{1 0}$ & $\mathbf{1 5}$ & $\mathbf{2 0}$ & $\mathbf{2 5}$ & $\mathbf{3 0}$ \\
\hline RSFO + TBHQ & 0.66 & 0.40 & 0.28 & 0.28 & 0.21 & 0.32 \\
\hline $\begin{array}{c}\text { RSFO + 0.5\% } \\
\text { clove oleoresin }\end{array}$ & 1.26 & 1.23 & 1.15 & 1.37 & 1.41 & 1.21 \\
\hline $\begin{array}{c}\text { RSFO + 1.5\% } \\
\text { clove oleoresin }\end{array}$ & 0.74 & 0.97 & 1.18 & 1.22 & 1.41 & 1.25 \\
\hline RSFO + 1\% ERF & 0.93 & 0.82 & 0.77 & 0.80 & 0.96 & 0.98 \\
\hline RSFO + 2\% ERF & 0.97 & 0.80 & 0.75 & 0.80 & 0.90 & 0.90 \\
\hline $\begin{array}{c}\text { RSFO + 1.5\% } \\
\text { clove oleoresin + } \\
2.5 \% \text { capsicum } \\
\text { oleoresin }\end{array}$ & 0.74 & 0.93 & 0.92 & 0.88 & 0.81 & 0.80 \\
\hline $\begin{array}{c}\text { RSFO + 2\% KEE } \\
+1.5 \% \text { clove } \\
\text { oleoresin }\end{array}$ & 0.43 & 0.48 & 0.54 & 0.57 & 0.51 & 0.53 \\
\hline $\begin{array}{c}\text { RSFO + 2\% KEE } \\
+2.5 \% \text { capsicum } \\
\text { oleoresin }\end{array}$ & 0.48 & 0.45 & 0.43 & 0.54 & 0.47 & 0.53 \\
\hline
\end{tabular}

Tables $1 \& 2$ and Figure 3 indicate the effect of clove oleoresin and ERF on oxidative stability of RSFO. Clove oleoresin showed pro-oxidant activity whereas ERF showed antioxidant activity. The pro-oxidant effect of clove is already noticed $[25,26]$. Eugenol generates the reactive oxygen species under alkaline conditions [27], indicating that under alkaline conditions, eugenol acts as a pro-oxidant. The oxidation of eugenol to vanillin under basic conditions is a developed process, where isomerization of eugenol to isoeugenol takes place initially [28]. The vanillin formation may take place via peroxide linkage generation at the allylic position of isoeugenol similar to curcumin [29]. It can be predicted from the structures of isoeugenol and vanillin (Figure 4). Thus, it implies that non-basic or polar environment has to be employed to stabilize the eugenol.

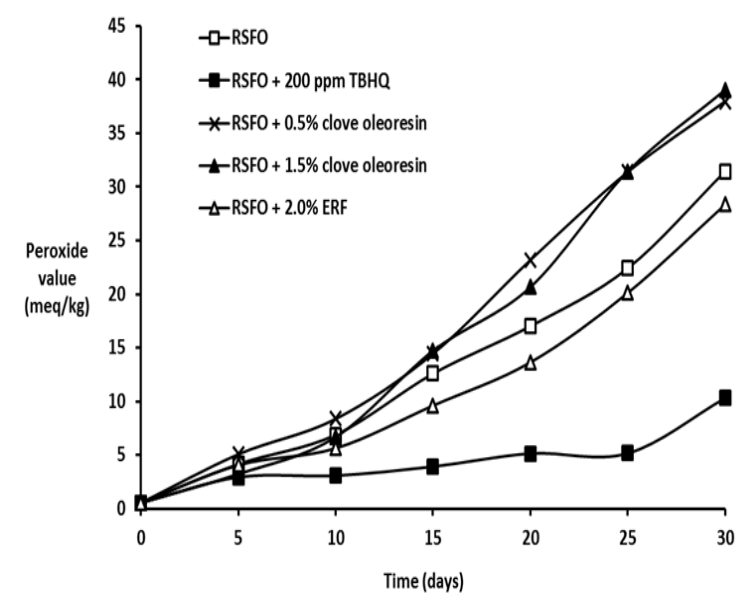

Figure 3: Effect of clove oleoresin on oxidative stability (peroxide formation) of RSFO at $60^{\circ} \mathrm{C}$.

Table 2: Effect of synergism of clove oleoresin with capsicum oleoresin and KEE on oxidative stability (totox value) of refined sunflower oil without antioxidant (RSFO) at $60^{\circ} \mathrm{C}$.

\begin{tabular}{|c|c|c|c|c|c|c|}
\hline \multirow[b]{2}{*}{$\begin{array}{l}\text { Sample Time } \\
\text { (days) }\end{array}$} & \multicolumn{6}{|c|}{ Totox $\dagger$} \\
\hline & 5 & 10 & 15 & 20 & 25 & 30 \\
\hline RSFO & $17.0 \pm 1.4$ & $22.6 \pm 1.5$ & $30.0 \pm 1.5$ & $40.1 \pm 1.6$ & $51.5 \pm 2.2$ & $70.9 \pm 3.9$ \\
\hline RSFO + TBHQ & $6.3 \pm 0.9$ & $8.2 \pm 0.8$ & $11.2 \pm 1.0$ & $14.0 \pm 1.1$ & $14.5 \pm 1.6$ & $26.3 \pm 2.8$ \\
\hline $\begin{array}{l}\mathrm{RSFO}+0.5 \% \text { clove } \\
\text { oleoresin }\end{array}$ & $20.9 \pm 0.7$ & $24.8 \pm 0.8$ & $30.6 \pm 1.7$ & $43.1 \pm 0.9$ & $64.6 \pm 3.2$ & $80.5 \pm 3.5$ \\
\hline $\begin{array}{l}\mathrm{RSFO}+1.5 \% \text { clove } \\
\text { oleoresin }\end{array}$ & $20.8 \pm 0.8$ & $24.7 \pm 1.1$ & $30.4 \pm 0.9$ & $42.5 \pm 2.1$ & $64.3 \pm 2.2$ & $79.7 \pm 3.3$ \\
\hline $\mathrm{RSFO}+1 \% \mathrm{ERF}$ & $19.2 \pm 1.2$ & $22.7 \pm 0.9$ & $27.9 \pm 1.1$ & $41.6 \pm 1.7$ & $57.7 \pm 2.5$ & $67.7 \pm 5.3$ \\
\hline $\mathrm{RSFO}+2 \% \mathrm{ERF}$ & $18.1 \pm 0.7$ & $21.5 \pm 0.5$ & $26.4 \pm 1.4$ & $38.3 \pm 0.4$ & $52.0 \pm 1.1$ & $61.5 \pm 3.6$ \\
\hline $\begin{array}{c}\text { RSFO }+1.5 \% \text { clove } \\
\text { oleoresin }+ \\
2.5 \% \text { capsicum } \\
\text { oleoresin }\end{array}$ & $8.3 \pm 0.2$ & $9.6 \pm 0.3$ & $11.6 \pm 0.4$ & $15.1 \pm 0.9$ & $18.2 \pm 0.5$ & $25.2 \pm 0.5$ \\
\hline $\begin{array}{c}\text { RSFO + } 2 \% \text { KEE + } \\
1.5 \% \text { clove } \\
\text { oleoresin }\end{array}$ & $5.2 \pm 0.3$ & $6.0 \pm 0.1$ & $7.1 \pm 0.4$ & $9.9 \pm 0.2$ & $11.7 \pm 0.3$ & $16.8 \pm 0.6$ \\
\hline $\begin{array}{c}\mathrm{RSFO}+2 \% \mathrm{KEE}+ \\
2.5 \% \text { capsicum } \\
\text { oleoresin }\end{array}$ & $4.3 \pm 0.1$ & $4.9 \pm 0.2$ & $5.7 \pm 0.1$ & $9.4 \pm 0.4$ & $10.9 \pm 0.4$ & $17.0 \pm 0.7$ \\
\hline
\end{tabular}




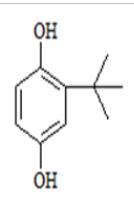

(a)

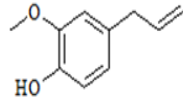

(b)

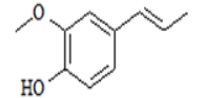

(c)

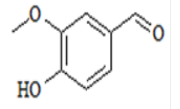

(d)
Figure 4: Chemical structures of (a) TBHQ (b) Eugenol (c) Isoeugenol (d) Vanillin.

The stabilization of eugenol and unveiling its antioxidant behaviour are correlated. The non-polar constituents were detected in clove oleoresin (Figure 1). On the other hand, oil used in the study was refined and hence, it lacked the polar constituents. Subsequently, scarcity of polar medium facilitated the degradation of eugenol. Therefore, OXF and totox values of blends containing clove oleoresin were higher than RSFO. During purification of clove oleoresin to isolate ERF, non-polar constituents were retained on the column. Thus, eugenol gets stabilized because of the absence of non-polar constituents. Hence, ERF revealed antioxidant activity. However, the results proved that the antioxidant activity of ERF was much lower than TBHQ even at higher concentration. This can be explained on the basis of structural difference between TBHQ and eugenol (Figure 4). TBHQ and eugenol are phenolic hydroxyl compounds. The phenolic compounds with electron donating group at ortho or para position are better antioxidants than those with meta-electron donating group [30,31].

Also, the size of the electron donating group like alkyl group mainly affects the antioxidant potential of the phenolic compounds [32]. TBHQ contains a bulky tertiary butyl group at ortho position to phenolic hydroxyl group and a hydroxyl group at para position to phenolic hydroxyl group. Thus, it contains two strong activating groups at ortho and para positions to phenolic hydroxyl group. In comparison to TBHQ, eugenol contains a moderately activating methoxy group at ortho position to phenolic hydroxyl group and a weakly activating allyl group at para position to phenolic hydroxyl group. Hence, the radical scavenging activity of eugenol is weak as compared to TBHQ. This implies that position as well as the electron donating strength of electron donating group is responsible for the antioxidant potential of a phenolic hydroxyl compound.

\section{Synergistic Antioxidant Activity of Clove Oleoresin, Capsicum Oleoresin with KEE}

Tables $1 \& 2$ and Figure 5 represent the synergistic antioxidant activity of clove oleoresin with capsicum oleoresin and KEE in RSFO, They also signify the synergistic antioxidant activity of capsicum oleoresin with KEE in RSFO. Capsicum oleoresin $(2.5 \%$ $\mathrm{w} / \mathrm{v}$ ) displayed synergistic antioxidant activity with lecithin and curcuminoids in RSFO [33]. Similarly, KEE (2\% w/v) exhibited synergistic antioxidant activity with curcuminoids [34] in RSFO. The combined effect of clove oleoresin with capsicum oleoresin illustrated moderate antioxidant activity whereas that of clove oleoresin with KEE revealed remarkable antioxidant activity in RSFO. Capsicum is reported to contain phenolic acids [35]. Nevertheless, the amount was incapable to overwhelm the impact of non-polar constituents present in clove oleoresin. Since polar medium was not provided, it must be possible that the antioxidant potential of capsicum oleoresin was utilized by both, RSFO and clove oleoresin to achieve stability.

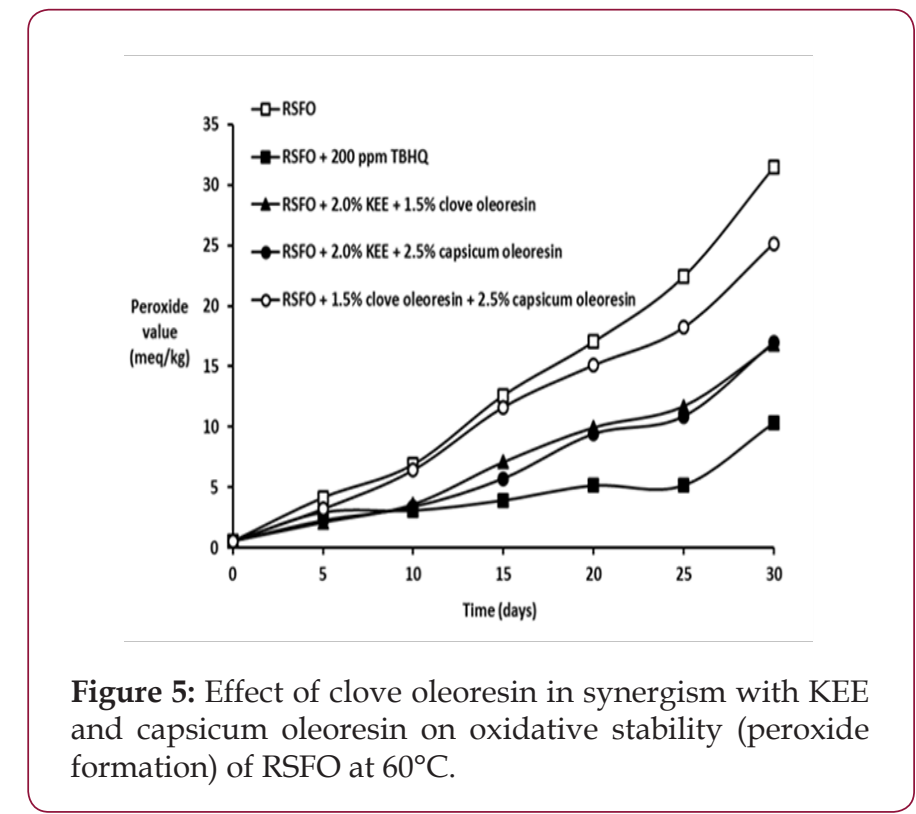

Though the OXF of the blend of clove oleoresin with capsicum oleoresin confirmed that the antioxidant activity was not much higher, the totox values of the blend were almost identical as those of TBHQ. This implies that the blend has the ability to stabilize peroxy compounds thereby inhibiting the formation of secondary degradation products like carbonyl compounds. In the blend of clove oleoresin with $\mathrm{KEE}$, the polar medium required to achieve the stability of eugenol was provided by KEE due to the presence of free fatty acids in it [9]. The oxidative stability of the blend depends on the concentration of polar and non-polar constituents. The concentration of polar constituents was increased by means of KEE. The polar constituents present in KEE surpassed the influence of non-polar constituents present in clove oleoresin. Consequently, eugenol present in clove oleoresin did not undergo degradation expressing its antioxidant activity. Hence, the synergistic antioxidant activity of the combination was notable.

Unlike clove oleoresin, capsicum oleoresin displayed antioxidant activity in RSFO, irrespective of the addition of KEE [36]. However, the combined effect of KEE and capsicum oleoresin indicated the similar antioxidant activity as that of KEE and clove oleoresin. The other constituents present in KEE besides antioxidants remained dormant when it is used in combination with capsicum oleoresin. The importance of these constituents is highly focused when they are utilized to generate a specific medium as required for clove oleoresin. Evidently, KEE acts as a good synergistic agent not only by imparting its own antioxidant activity but also by providing the polar medium to stabilize an antioxidant to avail its antioxidant activity. Both the blends, i.e., clove oleoresin with KEE and capsicum 
oleoresin with KEE showed low OXF, indicating that these two blends have the ability to prevent peroxide formation in RSFO. Since peroxide formation is low, generation of secondary oxidation products gets automatically reduced. Ultimately, the totox values of the blends being low restore the nutritive value of EFAs in RSFO.

\section{Conclusion}

The study of antioxidant activity of natural extracts is often unpredictable due to the presence of other constituents present in the extract. It is quite possible that a constituent possessing an antioxidant activity is present in the extract. However, because of the presence of other constituents, the extract as a whole exhibits pro-oxidant effect. This fact reveals that the antioxidant activity of an extract can be effectively utilized by suppressing the role of other constituents, by means of other extract. Thus, KEE inhibits the effect of non-polar constituents present in clove oleoresin. Hence, the antioxidant activity of the main constituent present as an antioxidant in clove oleoresin, i.e., eugenol is accomplished using KEE. Moreover, the non-toxicity of these natural antioxidants is valuable for various edible products including vegetable oils.

The activity of natural antioxidants as such was not comparable to synthetic antioxidants due to structural variation. However, two or more natural antioxidants can be used in proper synergism for better activity. KEE showed good synergistic antioxidant activity with capsicum oleoresin. Capsicum oleoresin can be used to suppress the degradation of eugenol. Consequently, the oxidative stability of the sunflower oil can be interpreted as the combined effect of all the constituents and the synergistic activity of the natural extracts can be used. The proper combination and proportion of natural antioxidants can win over the effect of other constituent present in the extract. Accordingly, the benefits of the natural extract can be utilized without purification.

\section{Acknowledgement}

This study was financially supported by Technical Education Quality Improvement Programme (TEQIP), Government of India and World Bank.

\section{References}

1. Spector AA (1999) Essentiality of fatty acids. Lipids 34(1): S1-S3.

2. Barlow SN (1990) Toxicological aspects of antioxidants used as food additives. In BJF Hudson (Eds.). Food Antioxidants. Elsevier, Amsterdam, Netherlands, pp. 253-307.

3. Moure A, Cruz JM, Franco D, Dominguez JM, Sineiro J, et al. (2001) Review: Natural antioxidants from residual sources. Food Chemistry 72(2): 145-171.

4. Nakatani N, Inatani R, Ohta H, Nishioka A (1986) Chemical constituents of pepper and application of food preservation. Naturally occurring antioxidative compounds. Environmental Health Perspectives 67: 135142.

5. Kohchi Y (1995) Antioxidative activity of spices and herbs. Foods and Food Ingredients Journal of Japan 163(7): 44-55.

6. Lagouri V, Boskou D (1995) Screening for antioxidant activity of essential oils obtained from spices. Developments in Food Science 37(1): 869879.
7. Li X, Xu JG (2016) Chemical composition and antioxidant activities of the oleoresin from the clove buds (Syzygium aromaticum). European Journal of Food Science and Technology 4(3): 16-24.

8. Nag A (2000) Stabilization of flaxseed oil with capsicum antioxidant. Journal of the American Oil Chemists Society 77(7): 799-800.

9. Singh G, Marimuthu P, Heluani C, Catalan C (2005) Chemical constituents and antimicrobial antioxidant potentials of essential oil and acetone extract of Nigella sativa seeds. Journal of the Science of Food and Agriculture 85(13): 2297-2306.

10. Rege SA, Momin SA, Wadekar SD, Pratap AP, Bhowmick DN (2014) Effect of demethoxycurcumin and bis demethoxycurcumin on antioxidant activity of curcumin in refined sunflower oil. Journal of Food Processing and Preservation 38(1): 296-303.

11. Pulikottil SJ, Nath S (2015) Potential of clove of Syzygium aromaticum in development of a therapeutic agent for periodontal disease. A Review. The South African Dental Journal 70(3): 108-115.

12. Machado M, Dinis AM, Salgueiro L, Custodio JB, Cavaleiro C, et al. (2011) Anti-giardia activity of Syzygium aromaticum essential oil and eugenol: Effects on growth, viability, adherence and ultrastructure. Experimental Parasitology 127(4): 732-739.

13. Shafi PM, Rosamma MK, Jamil K, Reddy PS (2002) Antibacterial activity of Syzygium cumini and Syzygium travancoricum leaf essential oils. Fitoterapia 73 (5): 414-416.

14. Muruganadan S, Srinivasan K, Chandra S, Tandan SK, Lal J, et al. (2001) Anti-inflammatory activity of Syzygium cumini bark. Fitoterapia $72(4)$ : 369-375.

15. Dibazar SP, Fateh S, Daneshmandi S (2015) Immunomodulatory effects of clove (Syzygium aromaticum) constituents on macrophages: In vitro evaluations of aqueous and ethanolic components. Journal of Immunotoxicology 12(2): 124-131.

16. Srinivasan K (2016) Biological activities of red pepper (Capsicum annuum) and its pungent principle capsaicin: A Review. Critical Reviews in Food Science and Nutrition 56(9): 1488-1500.

17. Haseena S, Aithal M, Das KK, Saheb SH (2015) Phytochemical analysis of Nigella sativa and its effect on reproductive system. Journal of Pharmaceutical Sciences and Research 7(8): 514-517.

18. Randhawa MA, Alenazi SA (2016) Neuropsychiatric effects of Nigella sativa (Black seed) - A Review. Alternative \& Integrative Medicine 5(1): $1-8$.

19. Nawar WW (1996) Chemistry In: YH Hui (Eds.). Bailey's Industrial Oils \& Fats. $5^{\text {th }}$ (Edn.). Vol.1, John Wiley \& Sons, New York, USA, pp. 397-425.

20. Gonzalez AT, Tamirano CW (1973) A new method for the determination of capsaicin in capsicum fruits. Journal of Food Science 38(2): 342-345.

21. Carrasco AH, Espinoza CL, Cardile V, Gallardo C, Cardona W, et al. (2008) Eugenol and its synthetic analogues inhibit cell growth of human cancer cells (Part I). Journal of the Brazilian Chemical Society 19 (3): 543-548.

22. AOCS (1994) In D Firestone (Eds.). Official methods and recommended practices of the American Oil Chemists' Society. ( $4^{\text {th }}$ Edition) American Oil Chemists Society. IL: Champaign, USA.

23. Rege SA, Momin SA (2017) Pro and antioxidant activity of curcuminoids with lecithin in sunflower oil. Ukrainian Food Journal 6(3): 494-503.

24. Ghada Am, Vassiliki 0 (2007) Antioxidant properties and composition of Majorana syriaca extracts. European Journal of Lipid Science and Technology 109(3): 247-255.

25. Zhang K (2015) Chemical composition and antioxidant activities of the essential oil from the clove buds (Syzygium aromaticum) toward various oxidative stresses in vitro. Agriculture and Food Sciences Research 2(1): 19-24. 
26. Lee ME, Kim E, Liu Y, March JC, Bentley WE, et al. (2014) Rapid and repeatable redox cycling of an insoluble dietary antioxidant: Electrochemical analysis. Journal of Agricultural and Food Chemistry 62(40): 9760-9768.

27. Atsumi T, Iwakura I, Fujisawa S, Ueha T (2001) Reactive oxygen species generation and photo-cytotoxicity of eugenol in solutions of various $\mathrm{pH}$. Biomaterials 22(12): 1459-1466.

28. Converti A, Aliakbarian B, Dominguez JM, Vazquez GB, Perego P (2010) Microbial production of biovanillin. Brazilian Journal of Microbiology 41(3): 519-530.

29. Masuda T, Hidaka K, Shinohara A, Maekawa T, Takeda Y, et al. (1999) Chemical studies on antioxidant mechanism of curcuminoid: Analysis of radical reaction products from curcumin. Journal of Agricultural and Food Chemistry 47(1): 71-77.

30. Cuvelier ME, Richard H, Berset C (1992) Comparison of the antioxidative activity of some acid-phenols: Structure-activity relationship. Bioscience Biotechnology and Biochemistry 56(2): 324-325.

31. Ali HM, Abo Shady A, Eldeen HAS, Soror HA, Shousha WG, et al. (2013) Structural features, kinetics and SAR study of radical scavenging and antioxidant activities of phenolic and anilinic compounds. Chemistry Central Journal 7: 53-62.

32. Khan MA, Shahidi F (2001) Effects of natural and synthetic antioxidants on the oxidative stability of Borage and Evening primose triacylglycerols. Food Chemistry 75(4): 431-437.

33. Rege SA, Momin SA (2017) Synergistic antioxidant activity of capsicum oleoresin, lecithin and curcuminoids in sunflower oil. International Journal of Food Processing Technology 4(1): 6-11.

34. Rege SA, Momin SA, Bhowmick DN, Pratap AP (2012) Stabilization of emulsion and butter like products containing essential fatty acids using kalonji seeds extract and curcuminoids. Journal of Oleo Science 61(1): 11-16.

35. Benzie IF (2003) Evolution of dietary antioxidants. Comparative Biochemistry and Physiology Part A: Molecular \& Integrative Physiology 136(1): 113-126.

36. Rege SA, Momin SA (2017) Synergistic antioxidant activity of capsicum oleoresin, lecithin and curcuminoids in sunflower oil. International Journal of Food Processing Technology 4(1): 6-11.

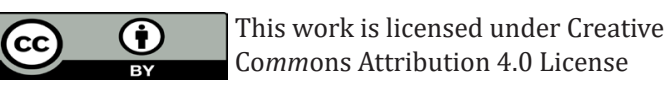

Submission Link: https://biomedres.us/submit-manuscript.php

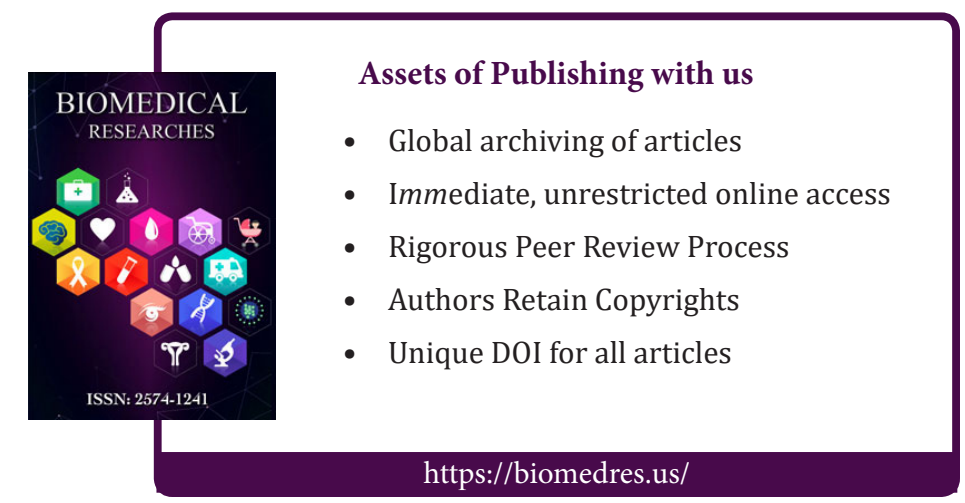

